\title{
Botany in Russia
}

$\mathrm{N}^{\mathrm{s}}$ UMBERS 1-5 of vol. 27 of the Bulletin of Applied Botany, of Genetics and Plant Breeding, issued at Leningrad, 1931, under the editorship of Prof. Vavilov, director of the Institute of Applied Botany, present a most impressive picture of the vigorous research along purely scientific lines, as well as into applied problems, which is proceeding in the U.S.S.R. In all, these five numbers contain more than two thousand pages. The papers are in Russian but are generally accompanied by English abstracts, upon which the following notes are based.

In the first number, G. A. Lewitsky summarises the work carried out in the cytological laboratory of the Institute of Plant Industry in the period 1927-30. The investigations have been governed by no less ambitious an aim than the discovery of the variations undergone by the nucleus during the process of evolution. This obviously involves studies linking cytology with systematics, and the work began with the genus Festuca. Here it was found that the polyploid multiplication, now so well known to the cytologist, penetrated into even the last subdivisions of the genus made by the systematist. The work then spread to the karyology of the whole great family of the Graminex, on which a monograph by N. P. Avdulov is now being published. This work has revealed another type of chromosome variation, affecting the individual units of the haploid group. In the Gramineæ, it is concluded, the basic number of chromosomes has diminished with evolution, from 12 and 10 in primitive types to 7 and 5 in more specialised stocks; along with this has proceeded a change from the tiny dumb-bell shaped chromosomes of the Oryzeæ and Panicoideæ to the larger worm-shaped chromosomes of the Poæoideæ.

Such researches necessitated the elaboration of methods of elucidating the morphology of the chromosomes, and the present volume consists largely of papers describing the methods thus developed and the results obtained. The relation of chromosome morphology to systematic affinity is elucidated in an intensive study of the sub-family Helleboreæ. A paper is also included upon the alterations induced in the chromosome by X-rays. The whole volume describes an intensive study upon fundamental cytological problems and it is to be hoped the results may be rendered more accessible to non-Russian workers.

No. 2 contains several important papers upon cereal breeding and upon genetical studies with other economic crops ; in particular, British cereal breeders will be interested in the studies of A. A. Orlov on the collection of barleys in the Institute of Plant Industry and of V. V. Suvorov on the Russian barleys. Orlov concludes that the barleys of Abyssinia and Eritrea are at the present time in a stage of an "impetuous creative process"; a re-arrangement of hereditary characters is proceeding actively and a number of new forms originating. Barleys are thus turning up which are very important from an agronomical point of view and have great biological plasticity.

Papers are also included upon the baking properties of mixtures of wheats and upon the connexion between physical and chemical characteristics of the wheat grain and the yield of flour. V. M. Kalashnikov has a paper upon breeding experiments with 'guayule' (Parthenium argentatum Gray) which is apparently to be tried in Russia as a home-grown source of rubber.

No. 3 contains more than 650 pages upon the forest studies and work on forest products carried out under the guidance of E. E. Kern. These studies of the possibilities of native trees and the behaviour of introduced species have naturally great interest for foresters.

No. 4 contains a more miscellaneous series of papers arising out of Russian genetical studies. T. Asseyeva continues her important studies of bud mutations in the potato. She has now more than 150 mutants under study and concludes that in an overwhelming majority of cases they show the structure of periclinal chimæras.

Percival had suggested that the number of veins in the coleoptile might have systematic value ( $A n n$. Bot., 41, 1927) and M. S. Jakovlev and E. I. Nikolaenko have tested this character over a much wider range of wheats. It appears to have systematic value but to lead to conclusions different from those drawn by Percival, especially in connexion with the Abyssinian wheats. Studies upon rice and upon the durum wheats of the northern Caucasus are also included in this part.

No. 5 contains the results of investigations carried out in the physiological laboratory of the Institute of Plant Industry under the general direction of N. A. Maximov. Naturally, therefore, studies on photo-periodism and upon water relations predom. inate. V. Rasumov has an interesting paper upon the effects of altering length of day upon tuber forma. tion in a number of races of Solanum which had been collected by the Institute in an expedition to South America. Tuber formation in $S$. tuberosum seems to be unaffected by day length, but in several other species a delay is induced by exposure to a longer day.

Jrene Borodin has studied the inter-action of important mineral nutrients upon the reaction of barley and millet to changes in length of day; nitrogen deficiency affects this reaction in barley in an opposite manner to phosphorus or potassium deficiency. The work points to the conclusion that the carbohydratenitrogen ratio is not the immediate cause of the change from the vegetative to the reproductive phase but an associated phenomenon. The same conclusion is suggested by V. Rasumov's study of the localisation of photo-periodic effect, which suggests, like similar American work, a direct effect of the period of illumination upon the growing centres.

Sophie Tageeva has an interesting study of photosynthesis under long and short day conditions, which leads to the conclusion that this process proceeds at about the same rate in the plant, however long the period of illumination. On the other hand, a 'long day' plant, like oats, shows under short day conditions a considerably greater accumulation of sub. stance than with a long day, an accumulation which must now be explained otherwise than by a more efficient photosynthetic activity.

Th. V. Bystrikov has a very interesting study of the root system of competing cultivated plants, in which what are defined as secondary crops oust prim. ary crop plants, like wheat, flax, etc., because of a more rapid development of aerial parts and a profuse branching of a more vigorous root system. He states that, in opposition to the views of the textbooks, the 
primary roots of the cereals do not die off early but remain intact and vital until the beginning of harvest.

Mme. Krasnosselsky-Maximov has attempted to elucidate the internal causes delaying reproduction in the winter forms of cereals. She is led to the conclusion that the winter forms contain a substance, possibly a hormone, which causes delay in reproduction.

The specific nature of the studies on moisture relations can only be briefly indicated. Ivan Vasiljev has a study of the influence of drought upon carbo. hydrate transformations in wheats. As usual, hydrolysis is increased with desiccation and synthesis with improvement in the water supply. J. N. Kondo has studied the influence of external, as well as internal, developmental factors, upon resistance to drought, whilst S. Kolotov examines the influence of soil moisture as a growth factor, and S. M. Ivanov attempts to determine the frost resistance of plants by changes in the electrical conductivity of the sap induced by frost injury.

\section{Priestley Celebration at the Chemical Society}

$\mathrm{P}$ RIESTLEY commemoration discourses were delivered before the Chemical Society on April 6 by Sir Philip Hartog, Prof. A. N. Meldrum, and Sir Harold Hartley, and there was also an exhibition of manuscripts, portraits, medals, books, apparatus, and personal mementoes lent by the Royal Society, Dr. Alexander Scott, Mr. G. H. Gabb, Mrs. Arundell Esdaile, Mr. W. C. Priestley, Dr. C. H. Spiers, and Dr. J. A. Newton Friend, or in the possession of the Chemical Society. Unfortunately, few of Priestley's instruments survive, as nearly all of them, together with his books and manuscripts, were destroyed when rioters sacked his house at Farhill, Birmingham, in 1791 .

Sir Philip Hartog dealt particularly with Priestley's own peculiar personality and history as a seientific man and theorist, and said that in some ways he had been singularly misjudged. Priestley had an amazing facility for mastering different subjects. $\mathrm{He}$ published some fifty works on theology, thirteen on education and history, about eighteen on political, social, and metaphysical subjects, and twelve books and some fifty papers dealing with physics, chemistry, and animal and vegetable physiology. He also knew Latin, Greek, French, German, Italian, Hebrew, Chaldee, Syrian, and began Arabic. The main purpose of his life was one of religion and piety ; his love of science, which he regarded as a relaxation, became obvious at a very early stage. $\mathrm{He}$ was the pioneer of the introduction of the teaching of science in schools.

Priestley had a clear vision of the value of hypothesis in scientific investigation, and repeatedly expressed his views on the relation of speculation to facts. Sir Philip Hartog examined and totally rejected the familiar statement that Priestley was 'unable to grasp' the new ideas of the composition of water, showing that he was at one time a convert to those ideas, that his attitude was based on his experimental observations, and that he declared himself ready to be influenced by any new and stronger evidence. Sir Philip Hartog summarised his brief appreciation of Priestley's personal qualities in the words : "Priestley was a glory not only of British science, but of British manhood".

Prof. Meldrum divided his discourse into two parts, showing in the first that Priestley, by his work on gases, made a contribution to science that is unique, and in the second exhibiting his work on nitrogen peroxide. $\mathrm{He}$ began by examining two problems which arose in the seventeenth century and were pursued in the eighteenth century by Hales, Black, and Cavendish: the absorption and production of air in general, and the existence of gases distinct from air and from one another. Priestley, who owed much to Cavendish, was self-trained in experimental science; he made the remarkable admission that his knowledge of chemistry was poor and that he was "not a practical chemist". Chemistry, up to his day, had been concerned so much with solids and liquids that its learning and processes were of little avail in work upon strange gases. Priestley was unique in being the first to handle gases boldly, easily, and quickly. Discussing what is meant by the 'discovery' of a substance, Prof. Meldrum said that Priestley got no credit for the discovery of nitrogen peroxide. He then gave an account of Priestley's preparation of nitric acid, his experiments on nitric oxide and nitrogen peroxide, and his production of nitro-sulphuric acid. The work showed his ardour for discovery, the resources of his mind, and his clever hands that nothing could escape.

Sir Harold Hartley said that Priestley's great service to chemistry was the extensiveness of his work, which revealed to chemists the variety of substances which could exist in the gaseous state, thoir individuality, and the importance of the part they played in chemical reactions. Priestley often ascribed his discoveries to chance, but in this he was unfair to himself, as he had a real genius for taking advantage of the opportunities that fortune offered him, and many of his researches showed that he could follow up a clue with a fine logical piece of investigation. Sir Harold Hartley described some of Priestley's work in connexion with the composition of the atmosphere, with the analysis of air, and with the practical applications of his discovery of oxygen. Priestley determined the relative density of gases, examined the combination of gases by volume, used solubility determinations as a means of identification, measured coefficients of thermal expansion and the conductivity of sound in gases, compared thermal conductivities, made the first experiments on gaseous diffusion, performed experiments with electricity, and was the first photo-chemist.

The secret of Priestley's genius as an investigator was his enthusiastic energy and curiosity, his fertility of mind, the ingenuity and enterprise with which he devised new experiments with the simplest means, his keen observation, his exceptional visual memory, and the rapidity with which he could develop a new investigation. There was behind everything the impelling force of his love for science, his devotion to experiment, and his boundless faith in the possibilities of new scientific discoveries. Dante's phrase well described Priestley's eager restless spirit, fearless and untiring in the defence of liberty and in the quest of truth: "con l'ali snelle ... del gran disio". 